\title{
Viral Etiology of Acute Respiratory Infection in Gansu Province, China, 2011
}

\author{
Guohong Huang ${ }^{1,39}$, Deshan $\mathrm{Yu}^{29}$, Naiying Mao', Zhen Zhu' ${ }^{1}$, Hui Zhang ${ }^{2}$, Zhongyi Jiang ${ }^{2}$, Hongyu $\mathrm{Li}^{2}$, \\ Yan Zhang ${ }^{1}$, Jing Shi ${ }^{1}$, Shuang Zhang ${ }^{1}$, Xinhua Wang ${ }^{2 *}$, Wenbo $\mathrm{Xu}^{1}{ }^{*}$
}

1 Key Laboratory of Medical Virology Ministry of Health, National Institute for Viral Disease Control and Prevention, Chinese Center for Disease Control and Prevention, Beijing, People's Republic of China, 2 Gansu Center for Disease Control and Prevention, Lanzhou, People's Republic of China, 3 Xinjiang Medical University, Urumqi, People's Republic of China

\begin{abstract}
Background: Acute respiratory infections (ARIs) are the leading cause of children and their leading killer. ARIs are responsible for at least six percent of the world's disability and death. Viruses are one of the most common agents causing ARIs. Few studies on the viral etiology and clinical characteristics of ARIs have been performed in the northwest region of China, including Gansu Province.

Methods: Clinical and demographic information and throat swabs were collected from 279 patients from January 1 st to December 30st, 2011. Multiplex RT-PCR was performed to detect 16 respiratory viral pathogens.

Results: 279 patients were admitted for ARIs. The patients aged from 1 month to 12 years, with the median age of 2 years. Of which, $105(37.6 \%)$ were positive for at least one pathogen. A total of 136 respiratory viral pathogens were identified from the 105 patients. Respiratory syncytial virus (RSV) was the most frequently detected pathogen (26.5\%, 36/136), followed by parainfluenza virus (PIV) 1-3 (22.1\%, 30/136), human rhinovirus (HRV) $(21.3 \%, 29 / 136)$, human coronavirus (CoV) $(10.3 \%, 14 / 136)$ and human adenovirus (HAdV) $(9.6 \%, 13 / 136)$. Influenza A (Flu A), human metapneumovirus (hMPV) and human bocavirus (BoCA) were found $4.4 \%, 3.7 \%$ and $2.2 \%$, respectively. Influenza B (Flu B) and seasonal influenza A $\mathrm{H} 1 \mathrm{~N} 1$ (sH1N1) were not detected. Single-infections were detected in 30.5\% (85/279) of cases. RSV was the most common pathogens in patients under 1 year and showed seasonal variation with peaks during winter and spring.

Conclusions: This paper presents data on the epidemiology of viral pathogens associated with ARIs among children in Gansu Province, China. RSV is most frequently detected in our study. The findings could serve as a reference for local CDC in drawing up further plans to prevent and control ARIs.
\end{abstract}

Citation: Huang G, Yu D, Mao N, Zhu Z, Zhang H, et al. (2013) Viral Etiology of Acute Respiratory Infection in Gansu Province, China, 2011. PLoS ONE 8(5): e64254. doi:10.1371/journal.pone.0064254

Editor: Dong-Yan Jin, University of Hong Kong, Hong Kong

Received October 5, 2012; Accepted April 12, 2013; Published May 14, 2013

Copyright: (c) 2013 Huang et al. This is an open-access article distributed under the terms of the Creative Commons Attribution License, which permits unrestricted use, distribution, and reproduction in any medium, provided the original author and source are credited.

Funding: This work was supported by the National Infectious Diseases Surveillance Program (2012ZX10004201, 2012ZX10004202, and 20121004-208). The funders had no role in study design, data collection and analysis, decision to publish, or preparation of the manuscript.

Competing Interests: The authors have declared that no competing interests exist.

*E-mail: wangxinhua1964@163.com (XW); wenbo_xu1@yahoo.com.cn (WX)

9 These authors contributed equally to this work.

\section{Introduction}

Acute respiratory infections (ARIs) are a group of diseases that include pneumonia, influenza, and respiratory syncytial virus (RSV). According to data from the World Health Organization (WHO), ARIs are responsible for at least six percent of the world's disability and death and cause a world disease burden of 94,037,000 (in terms of disability-adjusted life years (DALYs)) [1]. In terms of geographical distribution, $70 \%$ of children who died from ARIs are in Africa and Southeast Asia [2]. Respiratory syncytial virus (RSV), influenza A and B viruses (Flu A and B), human coronavirus $(\mathrm{CoV})$, human rhinoviruses (HRV), human adenoviruses (HAdV), human metapneumovirus (hMPV), and human bocavirus (BoCA) have been identified as the common causes of ARIs among populations [3,4].
Although the incidence of ARIs could be similar around the world, and several groups have reported the prevalence and clinical presentation of viral infections in China, studies conducted in remote and less well developed areas of China are scarce. This paper presents data on the epidemiology of viral pathogens associated with ARI among children in Gansu Province, which located in a relatively undeveloped area of China. It aims to provide basic data to direct local disease prevention and control measures.

\section{Results}

Patient characteristics

From January 1st to December 31st, 2011 , 279 eligible patients with ARIs were enrolled in this study. Ages ranged from 1 month to 12 years (median $=2$ years) and $153(54.8 \%, \mathrm{~N}=279)$ patients 
were aged between 1 and 6 years old. 183(65.6\%, $\mathrm{N}=279)$ were male $(\mathrm{M} / \mathrm{F}$ ratio $=1.9)$. The distribution of respiratory viruses in males and females had no difference $\left(\chi^{2}=0.009, \mathrm{P}=0.92\right)$. Demographic and clinical characteristics of patients are shown in Table 1. Among the 279 patients, 94.6\% (264/279) suffered from fever, which was the most common clinical symptom, followed by cough $(89.3 \%, 249 / 279)$ and expectoration $(49.8 \%$, 139/279). 39.4\% (110/279) of patients showed abnormal chest radiography. The average hospital stay duration was 6 days.

\section{Viral etiologies}

$105(37.6 \%, \mathrm{~N}=279)$ patients were positive for at least one pathogen. Single-infections accounted for $30.5 \%$ (85/279) of cases, co-infections were found in $4.3 \%(12 / 279)$ and multiple infections were $2.9 \%(8 / 279)$.

A total of 136 respiratory viral pathogens were identified from 105 patients. RSV was the most frequently detected (26.5\%, 36/ 136), followed by PIV 22.1\% (30/136), HRV 21.3 (29/136), CoV10.3\% (14/136) and HAdV 9.6\% (13/136). FluA, hMPV and BoCA were identified only $4.4 \%, 3.7 \%$, and $2.2 \%$, respectively. FluB and $\mathrm{sH} 1 \mathrm{Nl}$ were not detected in this study. (Table 2).

In the co-infections, PIV accounted for $41.7 \%(10 / 24)$ and PIV3 was the most frequently detected. PIV and CoV equally accounted for $29.6 \%(8 / 27)$ of the multiple-infections. PIV3 and CoV NL63 were the predominant type. The majority (12/13) of $\mathrm{HAdV}$ was detected as single infection.

\section{Viral pathogens distribution in different age group}

Table 3 shows the distribution of viral etiologies according to different age. RSV, HRV, PIV and CoV were detected in all groups. RSV was the most common pathogen in the patients

Table 1. Demographic and clinical characteristics of patients presenting ARIs.

\begin{tabular}{lll}
\hline & & \\
\hline Characteristics & Total (\%) $\mathbf{N}=\mathbf{2 7 9}$ & $\begin{array}{l}\text { Virus-positive (\%) } \\
\mathbf{N}=\mathbf{1 0 5}\end{array}$ \\
\hline Sex & & \\
Male & $183(65.6)$ & $69(65.7)$ \\
Female & $96(34.4)$ & $36(34.3)$ \\
Age groups(years) & & \\
$<1$ & $88(31.5)$ & $29(27.6)$ \\
\hline $1-6$ & $144(51.6)$ & $63(60.0)$ \\
$>6$ & $47(16.8)$ & $13(12.4)$ \\
Clinical symptoms & & $101(96.2)$ \\
Fever & $264(94.6)$ & $24(22.9)$ \\
Sore throat & $52(18.6)$ & $96(91.4)$ \\
Cough & $249(89.3)$ & $5(4.8)$ \\
Dyspnea & $19(6.8)$ & $8(7.6)$ \\
Polypnea & $23(8.2)$ & $0(0)$ \\
Chest pain & $8(2.9)$ & $50(47.6)$ \\
Expectoration & $139(49.8)$ & $47(44.8)$ \\
Moist rales & $32(47.3)$ & $8(7.2)$ \\
Dry Rales & $20(7.2)$ & \\
Abnormal chest & $110(39.4)$ & \\
radiography & & \\
Hospital duration & $6(5-9)$ & \\
\hline doi:10.1371/journal.pone.006425.t001 & \\
& & \\
\hline
\end{tabular}

under 1 year. The rates of $\operatorname{RSV}(17 / 153)$ and $\operatorname{HRV}(17 / 153)$ were similar in patients with the age between $1 \sim 6$ years. 11 of the 13 HAdV cases and all of the patients with hMPV infected also belonged to this group.

\section{Viral pathogens distribution in different season}

The respiratory viruses circulated in 2011 in Gansu Province were presented in Figure 1. RSV showed seasonal variation with peaks during winter and spring. HRV was detected more frequently from May to June. Seasonality of PIV infection was apparent during February to May. CoVs were distributed throughout the year except in June, July and September and did not show obvious seasonality. Other viral pathogens appeared sporadically during the year.

\section{Discussion}

This was the first study to detect multiple respiratory viruses in hospitalized children with ARIs in Lanzhou, Gansu Province, China. A total of 279 patients were enrolled from January to December 2011. Among the patients, $37.6 \%$ was positive for at least one virus, which was consistent with other studies $(34.6 \%-$ $62.6 \%$ ) [3,4,5-16]. But it was a little lower than the studies performed in Beijing, China [17], which was probably due to the lower economic status, lower health awareness or environmental factors in Gansu Province.

Our findings were consistent with other reports from Asia and China: RSV was the dominant cause of respiratory tract infection in children under 5 years [18-23]. RSV A was much more common than RSV B (34/2). RSV was reported to be responsible for 33.8 million cases of lower ARI in 2005, of which $96 \%$ was in developing countries [24]. It would be important for local pediatricians to use antibiotics cautiously when children are hospitalized with ARIs.

HRV has been known to be responsible for upper ARIs as well as for some lower respiratory infection in children [25-28]. Our findings showed the presence of HRV in all age groups. Most HRVs (23 of 29) were commonly detected as single infection, which agreed with the report of Bezerra et al [29]. The rest of the cases were co-infections with PIV, RSV.

HAdV was another important virus detected as single infection; only one case was detected as co-infection with HRV. It differed from the conclusion of Bezerra et al [29] in which HAdV was the most common pathogen in co-infection. HAdV was reported to be responsible for $5-10 \%$ of ARI in children [11]. Our findings confirmed this report, showing a detection rate of $9.6 \%(13 / 136)$, with 11 of the 13 patients infected by HAdV were under six years old.

The high detection rate of PIV and $\mathrm{CoV}$ in co-infections and multiple infections was an interesting finding. PIV was present in $50 \%(12 / 24)$ of co-infections. In particular, PIV3 and CoV NL63 were the most common types found. The much higher detection rate of CoV NL63 differed from previous epidemiological studies, in which $\mathrm{CoV} 229 \mathrm{E}$ and $\mathrm{CoV}$ OC43 were the most common types [30]. It is possible that the other types of $\mathrm{CoV}$ were not circulating in the area during the period of study. Meanwhile, the findings suggest that nosocomial infection cannot be ruled out.

Although hMPV had low prevalence in this study, only five hMPV infection cases were detected and were all aged between 1 to 6 years, which was in agreement with previous studies [31,32].

We found that RSV was detected mainly during winter and spring, which corresponds with the cold and dry seasons. Typical continental climate with cold and dry winters, and the large 
Table 2. Viral etiologies identified.

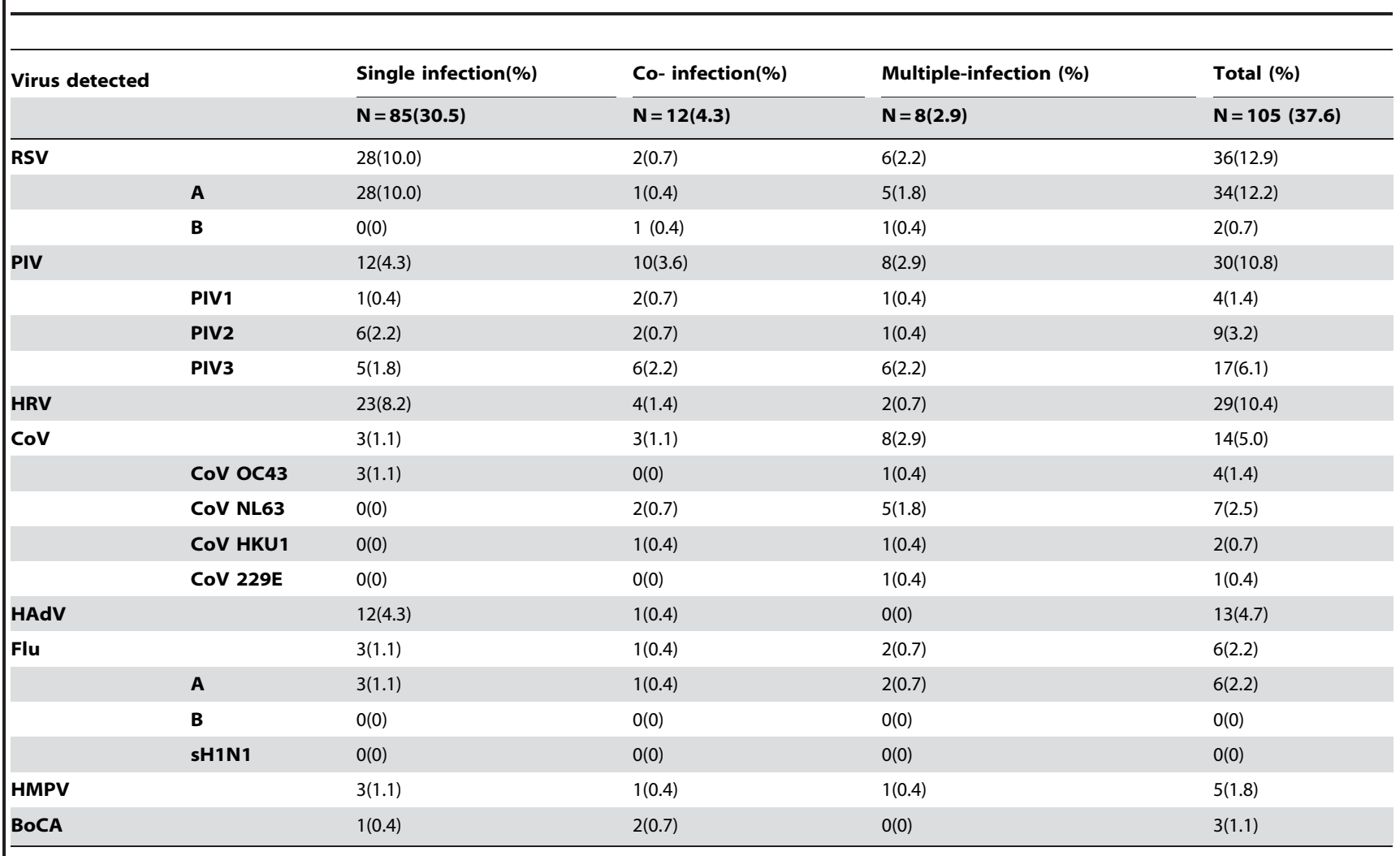

doi:10.1371/journal.pone.0064254.t002

difference between the indoor and outdoor temperatures in Gansu Province can easily induce respiratory diseases.

A multiple RT-PGR method was used in this study to detect sixteen common respiratory viruses [33]. This method was economical and fast in obtaining pathogen information, and both its sensitivity and specificity have been confirmed. However, there were some limitations in the current work: 1) a study spanning only one year and covering a single sentinel surveillance hospital

Table 3. Viral pathogens distribution in different age group.

\begin{tabular}{|c|c|c|c|c|c|c|}
\hline \multirow{2}{*}{ Virus detected } & \multicolumn{2}{|c|}{$<1(\mathrm{~N}=88)$} & \multicolumn{2}{|c|}{$1-6(N=153)$} & \multicolumn{2}{|c|}{$6-12(N=38)$} \\
\hline & $\mathbf{n}$ & $\%$ & $\mathbf{n}$ & $\%$ & $\mathbf{n}$ & $\%$ \\
\hline RSVA\&B & 17 & 19.3 & 17 & 11.1 & 2 & 5.3 \\
\hline PIV(1-3) & 7 & 8 & 15 & 9.8 & 8 & 21.1 \\
\hline HRV & 8 & 9.1 & 17 & 11.1 & 4 & 10.5 \\
\hline cov & 7 & 8 & 3 & 2 & 4 & 10.5 \\
\hline HAdV & 0 & 0 & 11 & 7.2 & 2 & 5.3 \\
\hline FluA\&B & 1 & 1.1 & 5 & 3.3 & 0 & 0 \\
\hline HMPV & 0 & 0 & 5 & 3.3 & 0 & 0 \\
\hline BoCA & 1 & 1.1 & 2 & 1.3 & 0 & 0 \\
\hline Single infection & 21 & 23.9 & 57 & 37.3 & 7 & 18.4 \\
\hline Co- infection & 5 & 5.7 & 6 & 3.9 & 1 & 2.6 \\
\hline $\begin{array}{l}\text { Multiple- } \\
\text { infection }\end{array}$ & 3 & 3.4 & 2 & 1.3 & 3 & 7.9 \\
\hline Positive cases & 29 & 33 & 65 & 42.5 & 11 & 28.9 \\
\hline
\end{tabular}

cannot recruit enough samples to analyze one particular pathogen; 2) only viral pathogens were detected in our study; bacterial pathogens that cause ARIs were not included, which prevented us from getting comprehensive data on the pathogens that cause ARIs in this region.

In conclusion, this study provided background information concerning the respiratory viral etiology in Lanzhou area of Gansu Province. Our findings could serve as a reference for local CDC in drawing up further plans to prevent and control ARIs. They will also help clinicians to choose medicines for patients with ARIs. Moreover, the use of multiple RT-PCR makes rapid, effective, and affordable detection for virus a reality in resource limited areas.

\section{Materials and Methods}

\section{Study population}

Between January 1st and December 31st, 2011, patients who met the inclusion criteria of ARI (aged under 12 years) were enrolled from the First Clinical Medical College of Lanzhou University, a large-scale general hospital in Lanzhou City, China.

All patients were hospitalization and eligible for an onset of illness within 5 days.

\section{Definitions}

1. Patients with ARIs must meet at least one of the inclusion criteria as follows:

1) fever (axillary temperature $\geq 37.2$ );

2) cough, sore throat, wheeze, expectoration, chest pain;

3) moist/dry rales; 

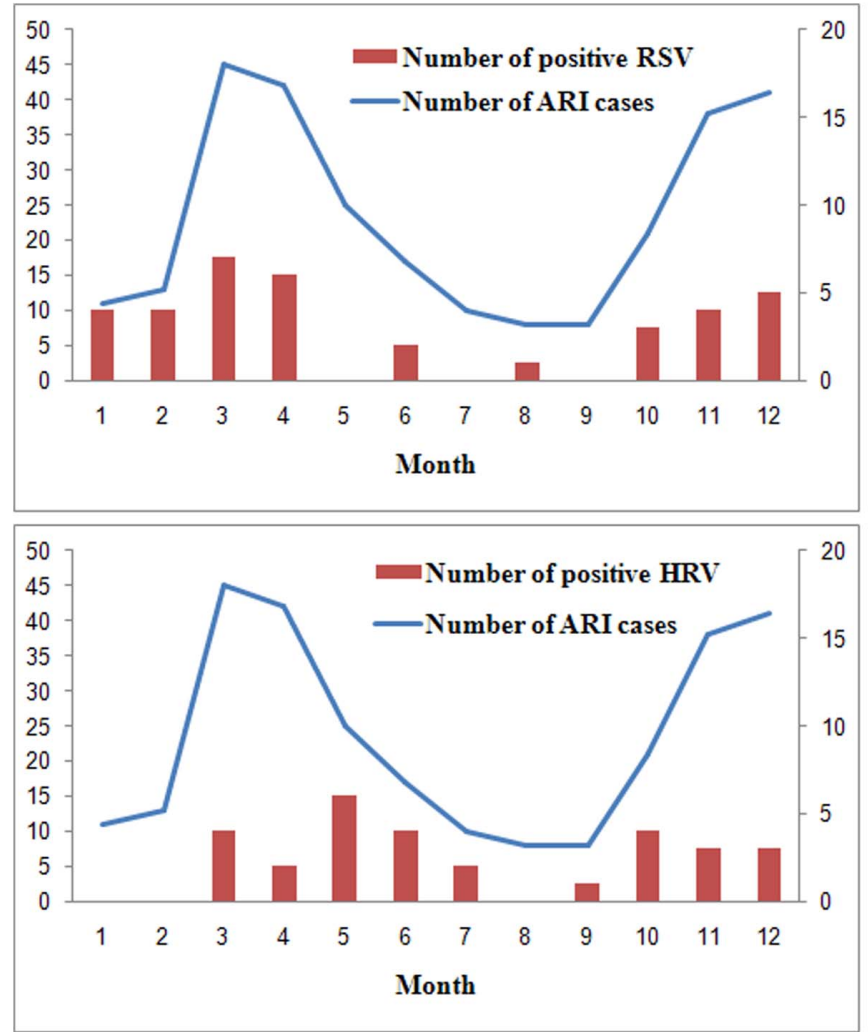

Figure 1. Viral pathogens distribution in different season. doi:10.1371/journal.pone.0064254.g001

Table 4. Primers information in this study.

\begin{tabular}{llll}
\hline & & & \\
\hline Target virus & Gene & $\begin{array}{l}\text { Final } \\
\text { concentration }\end{array}$ & $\begin{array}{l}\text { Amplification } \\
\text { size(bp) }\end{array}$ \\
\hline HRV & $5^{\prime}$-UTR & 1 uM & 144 \\
FLuB & M gene & 1 uM & 166 \\
CoV 229E & N gene & 1 uM & 182 \\
CoV OC43 & N gene & 1 uM & 200 \\
CoV HKU1 & N gene & 1 uM & 219 \\
sH1N1 & HA gene & 1 uM & 250 \\
FluA & M gene & 1 uM & 270 \\
PIV1 & HA gene & 1.75 uM & 283 \\
ADV & Hexon gene & 1.75 uM & 338 \\
RSVA & F gene & 1 uM & 158 \\
CoV NL63 & Polymerase & 1 uM & 174 \\
PIV2 & HA gene & 1 uM & 193 \\
HMPV & L gene & 2 uM & 207 \\
PIV3 & HA gene & 1.5 uM & 229 \\
RSVB & F gene & 2 uM & 278 \\
BOCA & NP1 & 2 uM & 290 \\
\hline & &
\end{tabular}

doi:10.1371/journal.pone.0064254.t004
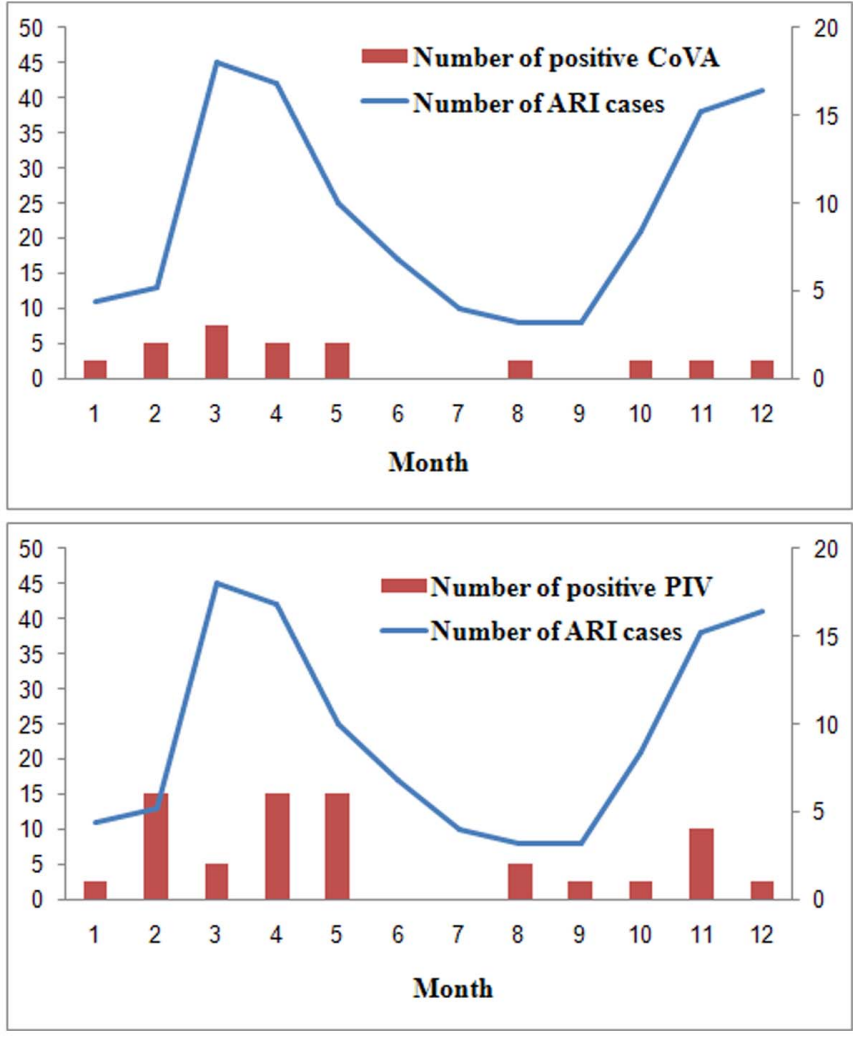

4) X-ray examination of lung inflammation showed punctate, patchy or uniform density shadow.

2. Single infection means only one viral pathogen detected in one sample; Co-infection means there are 2 viral pathogens detected in one sample; Multiple-infection means more than 3 viral pathogens detected in one sample.

\section{Specimen and data collection}

A total of 279 throat swab specimens were taken from 279 inpatients. The throat swab specimens were collected by attending physician in $2-\mathrm{mL}$ viral transport media, transported at $2^{\circ} \mathrm{C}-8^{\circ} \mathrm{C}$ and preserved at $-80^{\circ} \mathrm{C}$ until to Institute for Viral Disease Control and Prevention of the Chinese Center for Disease Control and Prevention (CDG), Beijing.

Clinical information including demographic characteristics, symptoms, signs treatments, duration of hospitalization, clinical diagnosis were documented in case report forms (CRFs).

This study was approved by the Ethics Review Committee of the Chinese CDC and all participants gave a signed informed consent.

\section{Extraction of nucleic acids and multiplex PCR}

The viral nucleic acid was directly extracted from the clinical specimens by using a QIAamp mini viral RNA extraction kit (Qiagen, Valencia, CA). RT-PCR was performed using a Qiagen OneStep RT-PCR kit (Qiagen, Valencia, CA) and GeneAmp 9700 thermal cycler (Applied Biosystems, Carlsbad, CA, USA). $25-\mu \mathrm{L}$ reaction mixture contained $5 \mu \mathrm{L} 5 \times$ PCR Mix, $1 \mu \mathrm{L}$ of dNTP Mix, $1 \mu \mathrm{L}$ of Enzyme Mix, $1.25 \mu \mathrm{L}$ of each primer 
mix(listed in Table 4), $0.1 \mu \mathrm{L}$ of RNase inhibitor, $10.9 \mu \mathrm{L}$ of RNase-DNase free water and $2 \mu \mathrm{L}$ of template RNA. PGR reaction conditions included an reverse transcription at $50^{\circ} \mathrm{C}$ for $30 \mathrm{~min}$, initial denaturation at $95^{\circ} \mathrm{C}$ for $15 \mathrm{~min}$, followed by the first 10 cycles of denaturation at $95^{\circ} \mathrm{C}$ for $30 \mathrm{~s}$, annealing at $55^{\circ} \mathrm{C}$ for $30 \mathrm{~s}$, extension at $72^{\circ} \mathrm{C}$ for $30 \mathrm{~s}$; the second 10 cycles of denaturation at $95^{\circ} \mathrm{C}$ for $30 \mathrm{~s}$, annealing at $65^{\circ} \mathrm{C}$ for $30 \mathrm{~s}$, extension at $72^{\circ} \mathrm{C}$ for $30 \mathrm{~s}$; the third 30 cycles of denaturation at $95^{\circ} \mathrm{C}$ for $30 \mathrm{~s}$, annealing at $48^{\circ} \mathrm{C}$ for $30 \mathrm{~s}$, extension at $72^{\circ} \mathrm{C}$ for $30 \mathrm{~s}$; and a final extension at $72^{\circ} \mathrm{C}$ for $7 \mathrm{~min}$. [33]. The PGR products were analyzed by capillary gel electrophoresis (QIAxel DNA High Resolution kit) and the reference size were shown in Table 4 . The detection of 16 respiratory viral pathogens was done in two groups: Group A was tested for the presence of FluA, FluB, sH1N1, HRV, CoV 229E/CoV OC43/CoV HKU1, PIV1, and HAdV; Group B was tested for the presence of RSVA/B, CoV NL63, PIV2/PIV3, HMPV and BoCA.

\section{References}

1. World Health Organization (2002) Burden of disease in DALYs by sex and mortality stratum in WHO regions, estimates for 2001. The World Health Report. 192-197.

2. Williams BG, Gouws E, Boschi-Pinto C, Bryce J, Dye G (2002) Estimates of world-wide distribution of child deaths from acute respiratory infections. Lancet Infect Dis 2(1): 25-32.

3. Mahony JB (2010) Nucleic acid amplification-based diagnosis of respiratory virus infections. Expert Rev Anti Infect Ther 8: 1273-92.

4. Beck ET, Henrickson KJ (2010) Molecular diagnosis of respiratory viruses. Future Microbiol 5: 901-916.

5. He J, Gong Y, Zhong WJ, Xu L, Liu Y, et al. (2011) Study on the viral etiology of acute respiratory tract infections in the Shanghai area during 2009-2010. J Microbes Infect 6: 90-96.

6. Ren L, Gonzalez R, Wang Z, Xiang Z, Wang Y, et al. (2009) Prevalence of human respiratory viruses in adults with acute respiratory tract infections in Beijing, 2005-2007. Clin Microbiol Infect 15: 1146-53.

7. Ren L, Gonzalez R, Xu J, Xiao Y, Li Y, et al. (2011) Prevalence of human coronaviruses in adults with acute respiratory tract infections in Beijing, China. J Med Virol 83: 291-7.

8. Druce J, Tran T, Kelly H, Kays M, Chibo D, et al. (2005) Laboratory diagnosis and surveillance of human respiratory viruses by PCR in Victoria, Australia, 2002-2003. J Med Virol 75: 122-129.

9. Esposito S, Bosis S, Niesters HG, Tremolati E, Begliatti E, et al. (2006) Impact of human coronavirus infections in otherwise healthy children who attended an emergency department. J Med Virol 78: 1609-15.

10. Maertzdorf J, Wang CK, Brown JB, Quinto J D, Chu M, et al. (2004) Real-time reverse transcriptase PCR assay for detection of human metapneumoviruses from all known genetic lineages. J Clin Microbiol 42: 981-6.

11. Bharaj P, Sullender WM, Kabra SK, Mani K, Cherian J, et al. (2009) Respiratory viral infections detected by multiplex PCR among pediatric patients with lower respiratory tract infections seen at an urban hospital in Delhi from 2005 to 2007 . Virol J 26;6: 89.

12. Brittain-Long R, Westin J, Olofsson S, Lindh M, Andersson LM (2009) Prospective evaluation of a novel multiplex real-time PCR assay for detection of fifteen respiratory pathogens-duration of symptoms significantly affects detection rate. J Clin Virol 47: 263-267.

13. Brittain-Long R, Andersson LM, Olofsson S, Lindh M, Westin J (2011) Seasonal variations of 15 respiratory agents illustrated by the application of a multiplex polymerase chain reaction assay. Scan J Infect Dis 44(1): 9-17.

14. Lam WY, Yeung AC, Tang JW, Ip M, Chan EW, et al. (2007) Rapid multiplex nested PCR for detection of respiratory viruses. J Clin Microbiol 45: 3631-40.

15. Berkley JA, Munywoki P, Ngama M, Kazungu S, Abwao J, et al. (2010) Viral etiology of severe pneumonia among Kenyan young infants and children. JAMA 303: 2051-2057.

16. Kim C, Ahmed JA, Eidex RB, Nyoka R, Waiboci LW, et al. (2011) Comparison of nasopharyngeal and oropharyngeal swabs for the diagnosis of eight respiratory viruses by real-time reverse transcription-PCR assays. PLoS One 6: e21610.

\section{Data analysis}

The count data adopted constituted the ratio and frequency table description, and a non-normal distribution of measurement data using the median to describe the central tendency and percentiles to describe the discrete tendency. The group ratios were compared using Pearson's $\chi 2$ test, with an inspection level $\alpha$ of 0.05 .

\section{Author Contributions}

Conceived and designed the experiments: WX XW. Performed the experiments: GH NM ZZ HZ ZJ HL YZ JS SZ DY. Analyzed the data: GH ZZ. Contributed reagents/materials/analysis tools: WX. Wrote the paper: GH DY NM ZZ WX.

17. Yu X, Lu R, Wang Z, Zhu N, Wang W, et al. (2012) Etiology and Clinical Characterization of Respiratory Virus Infections in Adult Patients Attending an Emergency Department in Beijing. PLoS One 7(2): e32174.

18. Mathisen M, Strand TA, Sharma BN, Chandyo RK, Valentiner-Branth P, et al. (2010) Clinical presentation and severity of viral community-acquired pneumonia in young Nepalese children. Pediatr Infect Dis J 29: e1-6.

19. Kim YK, Nyambat B, Hong YS, Lee CG, Lee JW, et al. (2008) Burden of viral respiratory disease hospitalizations among children in a community of Seoul, Republic of Korea, 1995-2005. Scand J Infect Dis 40: 946-953.

20. Izurieta HS, Thompson WW, Kramarz P, Shay DK, Davis RL, et al. (2000) Influenza and the rates of hospitalization for respiratory disease among infants and young children. N Engl J Med 342: 232-239.

21. Weber MW, Milligan P, Sanneh M, Awemoyi A, Dakour R, et al. (2002) An epidemiological study of RSV infection in the Gambia. Bull World Health Organ 80: 562-568.

22. Zou LR, Zhou J, Li H, Mo YL, Chen QX, et al. (2011) Etiology survey on virus of acute respiratory infection in Guangzhou from 2006 to 2009. Chinese Journal of Prevention Medicine. 45(9): 825-829.

23. Zhao B, Shen J, Gao Y, Yu X, Zhang X, et al. (2011) Detection for respiratory viruses in Shanghai with multiplex PCR from 2009 to 2010. Journal of Hygiene Research. 40(5): 635-637.

24. Nair H, Nokes DJ, Gessner BD, Dherani M, Madhi SA, et al. (2010) Global burden of acute lower respiratory infections due to respiratory syncytial virus in young children: a systematic review and meta-analysis. Lancet 375: 1545-1555.

25. Matthew J, Pinto Pereira LM, Pappas TE, Swenson CA, Grindle KA, et al. (2009) Distribution and seasonality of rhinovirus and other respiratory viruses in a crosssection of asthmatic children in Trinidad, West Indies. Ital J Pediatr 35: 16.

26. Pierangeli A, Gentile M, Di Marco P, Pagnotti P, Scagnolari C, et al. (2007) Detection and typing by molecular techniques of respiratory viruses in children hospitalized for acute respiratory infection in Rome, Italy. J Med Virol 79: 463468 .

27. Greenberg SB (2011) Update on rhinovirus and coronavirus infections. Semin Resoir Crit Care Med 32: 433-446.

28. Greer RM, McErlean P, Arden KE, Faux CE, Nitsche A, et al. (2009) Do rhinoviruses reduce the probability of viral co-detection during acute respiratory tract infections? J Clin Virol 45: 10-5.

29. Bezerra PGM, Britto MCA, Correia JB, Duarte MdCMB, Fonceca AM, et al.(2011) Viral and Atypical Bacterial Detection in Acute Respiratory Infection in Children Under five Years. PLoS ONE 6(4): e18928.

30. Greenberg SB (2011) Update on rhinovirus and coronavirus infections. Semin Resoir Crit Care Med 32: 433-446.

31. Van den Hoogen BG, de Jong JC, Groen J, Kuiken T, de Groot R, et al. (2001) A newly discovered human pneumovirus isolated from young children with respiratory tract disease. Nat Med 7: 719-24.

32. Schildgen V, van den Hoogen B, Fouchier R, Tripp RA, Alvarez R, et al. (2011) Human Metapneumovirus: Lessons Learned over the First Decade. Clin Microbiol Rev 24: 734-54.

33. Li J, Mao NY, Xu WB, Ma XJ. (2011) A GeXP based multiplex RT-PCR assay for simultaneous detection of twelve human respiratory viruses. Bing Du Xue Bao. 27(6): 526-32. (Chinese) 